OPEN ACCESS

Edited by:

Szilvia Anett Nagy,

University of Pécs, Hungary

Reviewed by: Joseph Kambeitz,

Ludwig Maximilian University of

Munich, Germany

Stijn Michielse

Maastricht University, Netherlands

${ }^{*}$ Correspondence:

Ksenija Vucurovic kvucurovic@chu-reims.fr

Specialty section:

This article was submitted to Neuroimaging and Stimulation,

a section of the journal

Frontiers in Psychiatry

Received: 26 November 2020

Accepted: 25 February 2021

Published: 20 April 2021

Citation:

Vucurovic K, Caillies S and Kaladjian A

(2021) Neural Correlates of

Mentalizing in Individuals With Clinical High Risk for Schizophrenia: ALE

Meta-Analysis.

Front. Psychiatry 12:634015.

doi: 10.3389/fpsyt.2021.634015

\section{Neural Correlates of Mentalizing in Individuals With Clinical High Risk for Schizophrenia: ALE Meta-Analysis}

\author{
Ksenija Vucurovic ${ }^{1,2 *}$, Stéphanie Caillies ${ }^{1}$ and Arthur Kaladjian ${ }^{1,3}$ \\ ${ }^{1}$ Laboratory Cognition, Santé, Société (C2S), Department of Psychology, University of Reims Champagne Ardenne, \\ Reims, France, ${ }^{2}$ Centre Rémois de Psychothérapie et Neuromodulation, Reims, France, ${ }^{3}$ Pôle Universitaire de Psychiatrie, \\ CHU de Reims, EPSM Marne, Reims, France
}

Psychotic disorder refers to a spectrum of disorders that have multiple etiologies, due to the complex interaction of biological and genetic vulnerability with familial and cultural factors. A clinical high risk (CHR) for schizophrenia is defined as the presence of brief, attenuated, or intermittent psychotic symptoms in non-schizophrenic individuals. The transition to schizophrenia appears significantly more frequent in this at-risk population than in the general population. Moreover, the ability to attribute mental states to others, known as mentalizing or theory of mind, and its neural correlates found in individuals with $\mathrm{CHR}$ are similar to those described in patients with schizophrenia. We have therefore explored neurofunctional correlates of mentalizing in individuals with $\mathrm{CHR}$ vs. healthy controls, in order to identify the differences in brain activation. A neural coordinate-based activation likelihood estimation meta-analysis of existing neuroimaging data revealed that three regions displayed decreased activation in individuals with $\mathrm{CHR}$, compared with healthy controls: the right temporoparietal junction, the right middle temporal gyrus, and the left precuneus. These results, combined with those in the literature, further support the hypothesis that abnormal activation of posterior brain regions involved in mentalizing correlates with psychotic symptoms in help-seeking individuals.

Keywords: theory of mind, schizophrenia, psychosis proneness, fMRI, social cognition

\section{INTRODUCTION}

Schizophrenia, a severe psychotic disorder, is among the leading causes of long-term disability worldwide (1). Therefore, better understanding of schizophrenia's emergence and disability correlates is one of the major challenges for modern psychiatric practice. Retrospective research has shown that individuals who develop schizophrenia display subclinical symptoms years before disease onset (2). Accordingly, the concept of clinical high risk (CHR) or ultra-high risk for psychotic disorders has emerged in the prospective literature $(3,4)$, and early interventions have been offered to help-seeking individuals in order to decrease their rate of transition to schizophrenia.

CHR state diagnosis is recognized as a prodromal period before schizophrenia onset and as such it is included in the latest version of Diagnostic and Statistical Manuel 5th version as "attenuated psychotic syndrome" (5). CHR is characterized by attenuated psychotic symptoms, brief limited intermittent psychotic symptoms, or basic symptoms (6). "Attenuated psychotic symptoms" refers to delusions, hallucinations, disorganized speech, or other psychotic symptoms present in an 
attenuated form. Reality testing is intact, but the symptoms are so frequent or severe that they cannot be ignored or discounted (7). Brief limited intermittent psychotic symptoms are frankly psychotic symptoms that do not last long enough for a diagnosis of schizophrenia to be made on the basis of current international criteria (8). Finally, basic symptoms are self-reported subtle, subclinical disturbances in stress tolerance and affective, cognitive, or perceptual drive, with full insight into their abnormal nature such that they motivate individuals to seek help $(9,10)$. Even though familial susceptibility to schizophrenia can be dissociated from CHR (11), it has been suggested that high genetic risk and functional decline are also diagnostic criteria for CHR (12).

It is thought that up to $20 \%$ of the general adult population have a psychotic-like experience (13). Nevertheless, individuals with CHR diagnostic criteria have a $16 \%-35 \%$ probability of developing a full-blown psychotic disorder within 2 years of CHR diagnosis $(4,14)$. Standardized validated instruments are used in clinical practice to identify individuals with $\mathrm{CHR}$.

In schizophrenia, mentalizing is constantly impaired at both the behavioral and neurological levels $(15,16)$. Mentalizing (or theory of mind, ToM) is a social cognition process that confers on us the ability to attribute mental states to others and to further understand that these states may be different from ours (17). It enables individuals to make sense of social communication and interactions and to predict the social behavior of others (18). It has been suggested that the processes underlying mentalizing deficits are genetically influenced and may constitute an intermediate phenotype of schizophrenia (19-21). Consistent with this, both individuals with a high familial risk for schizophrenia (11) and those with CHR not only display poorer psychosocial functioning (22), but also perform more poorly on mentalizing tasks (23-27) and have abnormal brain activity compared with healthy controls (11, 28-34). For example, activation of the medial prefrontal cortex (mPFC) during a ToM task, specifically a false-belief task, has been found to be negatively correlated with social anhedonia and social functioning in $\mathrm{CHR}(35,36)$, suggesting that the ToM processing impairment is related to relatively poor psychosocial functioning in this subclinical population.

The question now being asked is whether social cognition impairment is a marker of vulnerability to schizophrenia in individuals with $\mathrm{CHR}$. Investigating the neural correlates of impaired mentalizing in CHR could make it possible to identify neuroimaging markers of psychotic disorders, which could then be added to the clinical criteria when screening at-risk individuals. This approach could help us identify useful targets for therapeutic interventions in psychosocial rehabilitation programs and, in turn, understand more fully the link between poor social cognitive functioning and the correlated brain network without a medication bias.

Even though several studies have already investigated the underlying ToM neural correlates in $\mathrm{CHR}$, the small sample size of each study could lead to a lack of power. Reasoning that a meta-analysis of the existing neuroimaging data could help overcome this limitation, we carried out a systematic review of functional MRI studies of individuals with $\mathrm{CHR}$, in order to examine which brain region activation in individual studies would keep robust association with TOM task resolution. We expected to find evidence of abnormal brain activation in core regions of the mentalizing brain previously shown as abnormally activated in schizophrenia during TOM task resolution, namely the bilateral temporoparietal junction (TPJ), left superior temporal sulcus, medial prefrontal cortex (mPFC), and precuneus.

\section{METHODS AND MATERIALS}

\section{Literature Search and Selection}

We searched the following databases: MEDLINE, PsycINFO, Embase, and Current Contents. Relevant references from the retrieved papers were added to our database. Only whole-brain studies published in English until December 2020 were eligible for the review. We used the following keywords: at-risk mental states, ARMS, clinical high risk, CHR, ultra-high risk, UHR, psychosis, mentalizing, theory-of mind, perspective-taking, fMRI, PET, and brain. Paper selection is detailed in the PRISMA figure (Supplementary Material). Our procedure adhered to the 10 simple rules of Muller et al. (37) for neuroimaging metaanalysis. The present meta-analysis was registered in PROSPERO (no. CRD42019135862).

The inclusion criteria were (1) whole-brain neuroimaging (reported in the MNI or Talairach atlas) to compare individuals with CHR and healthy controls, (2) BOLD contrasts between the experimental condition (mentalizing) and the control condition, (3) mentalizing paradigm (featuring cartoons, video, or audio material) requiring participants to attribute mental states (emotions, intentions, beliefs) to others, and (4) diagnosis of CHR using validated clinical instruments and criteria (38).

Exclusion criteria were (1) CHR diagnosis based solely on familial susceptibility to schizophrenia, (2) brain damage or neurological disorder, (3) absence of a control group, and (4) mentalizing paradigm requiring either the attribution of a mental state to the self or emotion recognition, for although these processes are close to mentalizing, they do not fully overlap with the attribution of mental states to others (35, 39-42).

\section{Activation Likelihood Estimation Procedure}

We submitted the neuroimaging data to a neural coordinatebased activation likelihood estimation (ALE) meta-analysis, using GingerALE version 2.3.6 (brainmap.org/ale) to run the ALE algorithm (43). We converted the coordinates from MNI space to the Talairach space using the convert foci option implemented in the GingerALE toolbox (44-46) and used the more conservative ALE method of Turkeltaub et al. (46) for the ALE calculation. We ran a cluster-level inference threshold correction algorithm (45), with $p<0.001$ as the cluster-forming threshold and $p<0.05$ for cluster-level inference. The clusterlevel inference-corrected threshold set the minimum cluster volume such that only $5 \%$ of the simulated data's clusters exceeded this size. The minimum cluster size was $200 \mathrm{~mm}^{3}$. We performed the ALE analysis for all foci for ToM contrasts extracted from studies that compared individuals with $\mathrm{CHR}$ and healthy controls (HC). 
TABLE 1 | Activation clusters

\begin{tabular}{|c|c|c|c|c|c|c|}
\hline \multirow[t]{2}{*}{ Cluster } & \multirow[t]{2}{*}{ Location (BA) } & \multicolumn{3}{|c|}{ Talairach coordinates } & \multirow[t]{2}{*}{ ALE $\left(\times 10^{-2}\right)$} & \multirow[t]{2}{*}{ Cluster size $\left(\mathrm{mm}^{3}\right)$} \\
\hline & & $\mathbf{x}$ & $\mathbf{y}$ & $\mathbf{z}$ & & \\
\hline \multicolumn{7}{|c|}{$\mathrm{HC}>\mathrm{CHR}$} \\
\hline 1 & Right supramarginal gyrus (40) & 50 & -44 & 30 & 1,99 & 960 \\
\hline 2 & Right middle temporal Gyrus (21) & 59 & -30 & -10 & 1,77 & 560 \\
\hline 3 & Left precuneus (7) & -5 & -56 & 42 & 1,77 & 560 \\
\hline
\end{tabular}

BA, Brodmann Area; CHR, Clinical High Risk; HC, healthy controls; ALE, Activation Likelihood Estimation.

Centered cluster coordinates are reported.

\section{RESULTS}

The literature search yielded six studies (the research string is provided in Supplementary Figure 1), with seven experiments reporting 25 activation foci. Details about the studies we included, the paradigms they used, and the imaging characteristics are provided in Table 1. Two studies included individuals at familial high risk for schizophrenia $(35,47)$, but both studies focused on the clinical aspects of psychosis presented by the participants. Therefore, Marjoram et al. (47) compared individuals with high familial risk for schizophrenia with past or current attenuated psychotic symptoms with individuals with the comparable familial liability risk, but without those symptoms. Dodell-Feder et al. (35) included in their study the participants with both, familial liability to schizophrenia, and high scores on SIPS: Structured Interview for Prodromal Syndromes (Table 1). Therefore, the authors' consensus was that both studies meet typical CHR diagnostic criteria as defined by the field (48). A total of 91 individuals with CHR were compared with $110 \mathrm{HC}$. All the studies used fMRI. The ALE meta-analysis of the foci we extracted revealed decreased activation in the individuals with $\mathrm{CHR}$, compared with $\mathrm{HC}$, during mentalizing tasks in 1) a $960-\mathrm{mm}^{3}$ cluster extending from the right inferior parietal lobule (Talairach: $x=46, y=-48, z=26$; ALE $=0.02$; Brodmann area, BA 40) to the right supramarginal gyrus (Talairach: $x=54, y=$ $-34, z=34$; ALE $=0.02$; BA 40) and overlapping with the right TPJ (rTPJ), 2) a 560- $\mathrm{mm}^{3}$ cluster centered at $x=59, y=-30, z$ $=-10$ (Talairach) that covered the right middle temporal gyrus (MTG; BA 21), and 3) a 560- $\mathrm{mm}^{3}$ cluster that extended from $(-10,-58,38)$ to $(0,-50,46)$, centered at $(-5,-54,42)$, and overlapped with the precuneus. Detailed results are provided in Supplementary Table 1 . All the regions of decreased activation are shown in Figure 1, and the link to the NIFTI file is: https:// www.dropbox.com/s/ixpt8g5ykljmy9w/TOM\%20HCvsHRP_ ALE_C05_1k.nii?dl=0.

No significant cluster of increased activation was found in the individuals with $\mathrm{CHR}$ compared with $\mathrm{HC}$.

\section{DISCUSSION}

We investigated the neural correlates of mentalizing in a population with $\mathrm{CHR}$ by conducting a meta-analysis of the neuroimaging literature. Even though only a small number of studies were eligible for quantitative meta-analysis, we obtained a significant result with good statistical robustness for three brain regions, which appeared to be insufficiently activated in comparison with HC: right TPJ, right MTG (BA 21), and left precuneus. All three regions are critically involved in the processing of social cognitive information in neurotypical development (49).

\section{Brain Function of Identified Areas}

The right MTG (BA 21) was described as being involved in the processing of affective prosody in speech $(50,51)$, the auditory processing of complex sounds (52), visual memory function (53), and social cognition, particularly mentalizing during nonverbal tasks (54). The right TPJ is a highly integrative brain structure that enables high-order cognitive processing to take place. In social cognition, it is thought to be particularly involved in attention shift to unexpected stimuli and the attribution of intentions/beliefs to others (55). It has been suggested that the rTPJ can be divided into two functional domains: an anterior one involved in both ToM and attention and a posterior one that seems to be exclusively involved in $\operatorname{ToM}(55,56)$. Disruption of the rTPJ impairs probabilistic belief updating (57). Finally, the precuneus is involved in a variety of cognitive processes, comprising the integration of environmental information and self-centered mental imagery strategies for its anterior portion (58), and episodic memory retrieval (58) and affective response to pain (59) for its posterior portion. The precuneus is reported to be involved in conscious information processing and closely connected to the mPFC, bilateral TPJ, and thalamus via the default mode network (60).

Our results are in line with volumetric studies of mentalizing in CHR that have found reduced gray-matter volume in the right superior temporal gyrus, left precuneus, left medial frontal gyrus, right middle frontal gyrus, bilateral parahippocampal/hippocampal regions and bilateral anterior cingulate, compared with HC (61). These authors further suggested that reduced gray-matter volume in the right inferior frontal gyrus and right superior temporal gyrus is predictive of the transition to psychotic disorder.

\section{Comparison With Genetic Risk for Schizophrenia}

The literature indicates that individuals with familial high risk (FHR) for schizophrenia exhibit decreased mPFC activation and increased activation of the right MTG and posterior 


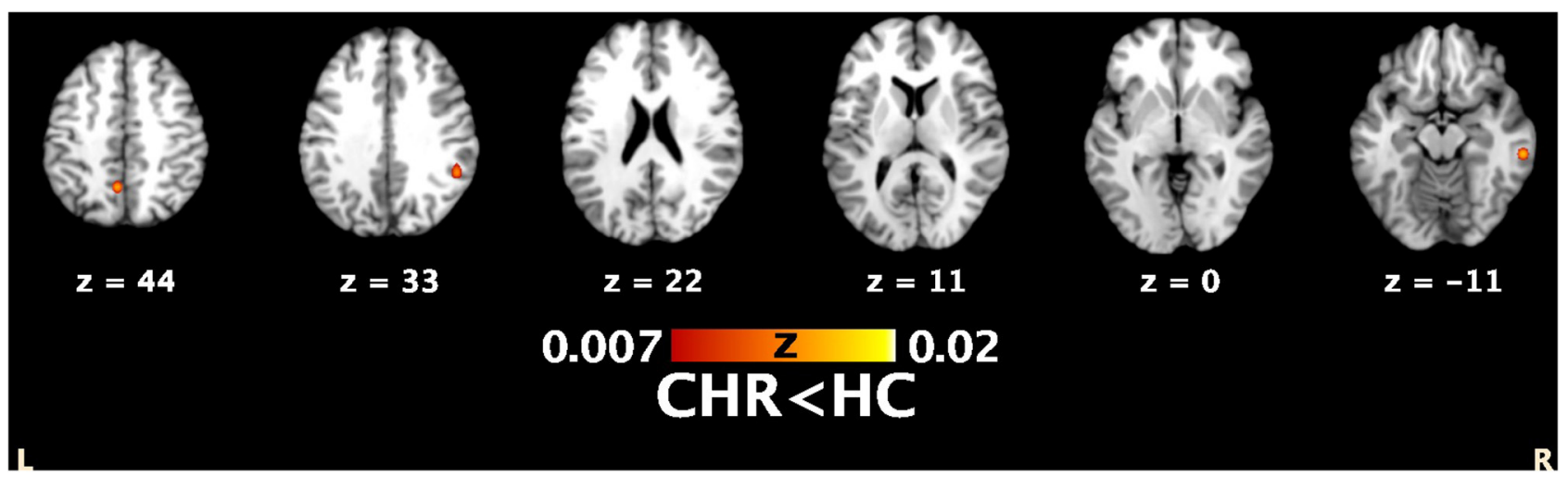

FIGURE 1 | Functional clusters from comparison analysis between mentalizing networks showing significant neurofunctional convergence of decreased activation in individuals with CHR vs. healthy controls in following brain structures (from left to right): the left precuneus, the right parieto-temporal junction and right middle temporal gyrus. Mask dimensions $=80 \times 96 \times 70$; number of within-brain voxels = 226,657; number of foci $=25$; number of experiments = 7; maximum ALE score $=0.02$; threshold method $=$ cluster-level inference; thresholding value $=0.05$; thresholding permutations $=1,000 ;$ cluster-forming value $=0.001$. Figure created using Mango (http://ric.uthscsa.edu/mango).

cingulate cortex during a mentalizing task (11). However, the results of fMRI studies comparing patients in acute psychosis and after recovery suggest that decreased $\mathrm{mPFC}$ activation is state-dependent $(47,62)$. In line with results observed in FHR, volumetric studies in schizophrenia have consistently described a positive correlation between ToM deficits and gray-matter reduction in the $\mathrm{mPFC}(63-68)$. In a large metaanalysis of ToM neural correlates, Schurz et al. (49) found that the mPFC is strongly activated in false-belief, strategic games, and trait judgment tasks and to a far lesser extent in social interactions, reading the mind in the eyes, and rational actions. The ventral mPFC is also described as being involved in processing explicit and implicit information about oneself and others in abstract and evaluative terms that enable individuals to understand complex psychological aspects of other people (69-72) or decouple mental states from their environment (73, 74). Barbey et al. (75) additionally claimed that the ventral mPFC specifically enables individuals to draw inferences about complex relations. It was therefore surprising not to find abnormal mPFC activation in our CHR meta-analysis. Even though some of the participants with CHR included in our meta-analysis had a genetic predisposition for schizophrenia, the major difference from relatives who were not affected by schizophrenia was the presence of attenuated psychotic symptoms, albeit at the subthreshold level. Consistently with this, Monhke et al. (11) demonstrated that activation of the right MTG and posterior cingulate cortex is correlated in FHR individuals with attenuated paranoid ideation. Abnormal mPFC activation during mentalizing tasks may therefore be an endophenotypic marker of schizophrenia related to genetic vulnerability (11), while abnormal activation of the temporoparietal cortex and precuneus may be related more to the psychopathology of psychotic disorders.

\section{Comparison With Schizophrenia}

Three recent coordinate-based meta-analyses explored brain activation during mentalizing tasks resolution in schizophrenia compared to healthy controls [(76), 73, 74]. Both (76), and Kronbichler et al. (77), used Seed-Based Mapping methodology and concordantly found spread abnormalities in brain activation patterns in the patients group. Both groups of authors reported decreased activation of the mPFC, left orbitofrontal cortex, medial parieto-occipital cortex, right premotor areas, cingulate and lingual gyri [(76), 73]. Interestingly, in both meta-analyses, different activation of the bilateral parietotemporal junction was described, with decreased activation of posterior ventral portion and increased activation in the posterior dorsal portion in schizophrenia patients [(76), 73], suggesting abnormal brain functioning of this area of the brain in patients. Our team led the comparative neuralcorrelates-based meta-analysis of mentalizing and empathy in schizophrenia patients using ALE methodology. We found decreased left TPJ activation during mentalizing tasks and decreased right ventrolateral PFC activation during emotion attribution tasks (78). Those literature data compared with the results of this meta-analysis in CHR, suggest abnormal activation in brain regions related to mentalizing in both schizophrenia and $\mathrm{CHR}$, with diverging activation patterns in the right TPJ. Moreover, in patients with schizophrenia, the rTPJ is functionally connected to the hippocampus, fusiform gyrus, and MTG during mental state inference (79). Pauly et al. (80) found a positive correlation between positive symptoms and activation of the parahippocampus that led them to suggest a possible increase in emotion-related responses as the disease progresses. The opposite pattern of rTPJ activation in schizophrenia and CHR may therefore be related to more severe psychopathology in schizophrenia and more particularly to a cognitive mechanism of over-attribution of mental states or over-generation of hypotheses, described as hyper-ToM (81). Chambon et al. (82) postulated that the physiopathological mechanism, whereby undue weight is given to prior expectations in schizophrenia with positive symptoms, stems from the abnormal encoding of prediction error signals in dopamine-rich brain areas (83). 


\section{LIMITATIONS AND CONCLUSION}

Our study had several limitations. As our meta-analysis was based on the available literature, it may have been affected by the potential publication bias against null results. Furthermore, the tasks used to assess neural correlates during mentalizing may have had limited ecological validity. Although very few experiments were included in our meta-analysis, we explored more than 20 foci, which is the threshold suggested by different authors for meta-analysis validity $(37,84)$.

In conclusion, our findings suggest that individuals with CHR may not have some fully functional specialized neural correlates for inferring the mental states of others. We found decreased activation of posterior brain areas related to mentalizing in these individuals that may be related to their increasing psychopathology. Longitudinal studies should address the neurological markers that predict the transition to schizophrenia in this population.

\section{AUTHOR CONTRIBUTIONS}

$\mathrm{KV}$, SC, and AK contributed to the study conception and design. $\mathrm{KV}$ realized the systematic review of literature, done the first selection of relevant articles, data collection, statistical analysis,

\section{REFERENCES}

1. Owen MJ, Sawa A, Mortensen PB. Schizophrenia. Lancet. (2016) 388:8697. doi: 10.1016/S0140-6736(15)01121-6

2. Klosterkötter J, Hellmich M, Steinmeyer EM, Schultze-Lutter F. Diagnosing schizophrenia in the initial prodromal phase. Arch Gen Psychiatry. (2001) 58:158164. doi: 10.1001/archpsyc.58.2.158

3. Miller TJ, McGlashan TH, Rosen JL, Somjee L, Markovich PJ, Stein K, et al. Prospective diagnosis of the initial prodrome for schizophrenia based on the Structured Interview for Prodromal Syndromes: preliminary evidence of interrater reliability and predictive validity. Am J Psychiatry. (2002) 159:8635. doi: 10.1176/appi.ajp.159.5.863

4. Yung AR, Yuen HP, McGorry PD, Phillips LJ, Kelly D, Dell'Olio M, et al. Mapping the onset of psychosis: the Comprehensive Assessment of At-Risk Mental States. Aust N Z J Psychiatry. (2005) 39:96471. doi: 10.1080/j.1440-1614.2005.01714.x

5. Fusar-Poli P, De Micheli A, Cappucciati M, Rutigliano G, Davies C, RamellaCravaro V, et al. Diagnostic and prognostic significance of DSM-5 attenuated psychosis syndrome in services for individuals at ultra high risk for psychosis. Schizophr Bull. (2018). 44:264-75. doi: 10.1093/schbul/sbx055

6. Dutt A, Tseng HH, Fonville L, Drakesmith M, Su L, Evans J, et al. Exploring neural dysfunction in 'clinical high risk' for psychosis: a quantitative review of fMRI studies. J Psychiatr Res. (2015) 61:122134. doi: 10.1016/j.jpsychires.2014.08.018

7. Yung AR, Nelson B. Young people at ultra high risk for psychosis: a research update. Early Interv Psychiatry. (2011) 5:5257. doi: 10.1111/j.1751-7893.2010.00241.x

8. McGlashan T, Walsh BC, Woods SW. The Psychosis Risk Syndrome: Handbook for Diagnosis and Follow-up. New York, NY: Oxford University Press (2010).

9. Schultze-Lutter F. Subjective symptoms of schizophrenia in research and the clinic: the basic symptom concept. Schizophr Bull. (2009) 35:58. doi: $10.1093 /$ schbul/sbn139

10. Schultze-Lutter F, Ruhrmann S, Klosterkötter J. Early detection of psychosis -establishing a service for persons at risk. Eur Psychiatry. (2009) 24:110. doi: 10.1016/j.eurpsy.2008.08.004

11. Mohnke S, Erk S, Schnell K, Romanczuk-Seiferth N, Schmierer P, Romund $\mathrm{L}$, et al. Theory of mind network activity is altered in subjects with and drafted manuscript preparation. SC and AK done the final selection of included articles and supervised the research. All authors reviewed the results and approved the final version of the manuscript.

\section{FUNDING}

This work was supported by the collaborative project between the University of Reims Champagne-Ardenne (URCA) and the University Hospital of Reims (CHU de Reims), called Projet Hospitalo-Universitaire (PHU), Social Cognition and Neurodevelopmental disorders (NDev-X), which was awarded to AK.

\section{ACKNOWLEDGMENTS}

We would like to thank Eric Fakra and Gilles Lafargue for their valuable comments on this research.

\section{SUPPLEMENTARY MATERIAL}

The Supplementary Material for this article can be found online at: https://www.frontiersin.org/articles/10.3389/fpsyt. 2021.634015/full\#supplementary-material familial liability for schizophrenia. Soc Cogn Affect Neurosci. (2015) 11:299307. doi: $10.1093 / \mathrm{scan} / \mathrm{nsv} 111$

12. Andreou C, Borgwardt S. Structural and functional imaging markers for susceptibility to psychosis. Mol Psychiatry. (2020) 25:2773-85. doi: 10.1038/s41380-020-0679-7

13. Hanssen MS, Bijl RV, Vollebergh W, van Os J. Self-reported psychotic experiences in the general population: a valid screening tool for DSM-III-R psychotic disorders? Acta Psychiatr Scand. (2003) 107:369377. doi: 10.1034/j.1600-0447.2003.00058.x

14. Cannon TD. Brain biomarkers of vulnerability and progression to psychosis. Schizophr Bull. (2015) 42:S127-132. doi: 10.1093/schbul/sbv173

15. Green MF. Impact of cognitive and social cognitive impairment on functional outcomes in patients with schizophrenia. J Clin Psychiatry. (2016) 77(Suppl 2):811. doi: $10.4088 / J C P .14074$ sulc.02

16. van Os J, Kapur S. Schizophrenia. Lancet.

(2009) 374:635645. doi: 10.1016/S0140-6736(09)60995-8

17. Premack D, Woodruff G. Does the chimpanzee have a theory of mind? Behav Brain Sci. (1978) 1:515-26. doi: 10.1017/S0140525X00076512

18. Frith CD, Frith U. The neural basis of mentalizing. Neuron. (2006) 50:531534. doi: 10.1016/j.neuron.2006.05.001

19. Gottesman II, Gould TD. The endophenotype concept in psychiatry: etymology and strategic intentions. Am J Psychiatry. (2003) 160:636645. doi: 10.1176/appi.ajp.160.4.636

20. Meyer-Lindenberg A, Weinberger DR. Intermediate phenotypes and genetic mechanisms of psychiatric disorders. Na Rev Neurosci. (2006) 7:818827. doi: 10.1038/nrn1993

21. Walter H, Schnell K, Erk S, Arnold C, Kirsch P, Esslinger C, et al. Genetic risk for schizophrenia impacts Theory-of-Mind-related brain activation. Mol Psychiatry. (2011) 16:353. doi: 10.1038/mp.2011.25

22. Ventura J, Hellemann GS, Thames AD, Koellner V, Nuechterlein KH. Symptoms as mediators of the relationship between neurocognition and functional outcome in schizophrenia: a meta-analysis. Schizophr Res. (2009) 113:189199. doi: 10.1016/j.schres.2009.03.035

23. Koivukangas J, Björnholm L, Tervonen O, Miettunen J, Nordström T, Kiviniemi V, et al. White matter structure in young adults with familial risk for psychosis-the oulu brain and mind study. Psychiatry Res. (2015) 233:388393. doi: 10.1016/j.pscychresns.2015.06.015 
24. Piskulic D, Liu L, Cadenhead KS, Cannon TD, Cornblatt BA, McGlashan $\mathrm{TH}$, et al. Social cognition over time in individuals at clinical high risk for psychosis: findings from the NAPLS-2 cohort. Schizophr Res. (2016) 171:176181. doi: 10.1016/j.schres.2016.01.017

25. Stanford AD, Messinger J, Malaspina D, Corcoran CM. Theory of Mind in patients at clinical high risk for psychosis. Schizophr Res. (2011) 131:1117. doi: 10.1016/j.schres.2011.06.005

26. Versmissen D, Janssen I, Myin-Germeys I, Mengelers R, Campo JA, van Os J, et al. Evidence for a relationship between mentalising deficits and paranoia over the psychosis continuum. Schizophr Res. (2008) 99:103110. doi: 10.1016/j.schres.2007.09.024

27. Yong E, Barbato M, Penn DL, Keefe RS, Woods SW, Perkins DO, et al. Exploratory analysis of social cognition and neurocognition in individuals at clinical high risk for psychosis. Psychiatry Res. (2014) 218:3943. doi: 10.1016/j.psychres.2014.04.003

28. Brüne M, Ozgürdal S, Ansorge N, von Reventlow HG, Peters S, Nicolas V, et al. An fMRI study of "theory of mind" in at-risk states of psychosis: comparison with manifest schizophrenia and healthy controls. Neuroimage. (2011) 55:329337. doi: 10.1016/j.neuroimage.2010.12.018

29. Derntl B, Michel TM, Prempeh P, Backes V, Finkelmeyer A, Schneider F, et al. Empathy in individuals clinically at risk for psychosis: brain and behaviour. $\mathrm{Br}$ J Psychiatry. (2015) 207:407-13. doi: 10.1192/bjp.bp.114.159004

30. Goghari VM, Sanford N, Spilka MJ, Woodward TS. Task-related functional connectivity analysis of emotion discrimination in a family study of schizophrenia. Schizophr Bull. (2017) 43:1348-62. doi: 10.1093/schbul/sbx004

31. Ho KK, Lui SS, Hung KS, Wang Y, Li Z, Cheung EF, et al. Theory of mind impairments in patients with first-episode schizophrenia and their unaffected siblings. Schizophr Res. (2015) 166:18. doi: 10.1016/j.schres.2015.05.033

32. Modinos G, Renken R, Shamay-Tsoory SG, Ormel J, Aleman A. Neurobiological correlates of theory of mind in psychosis proneness. Neuropsychologia. (2010) 48:37153724. doi: 10.1016/j.neuropsychologia.2010.09.030

33. van der Meer L, Groenewold NA, Pijnenborg M, Aleman A. Psychosisproneness and neural correlates of self-inhibition in theory of mind. PLoS ONE. (2013) 8:e67774. doi: 10.1371/journal.pone.0067774

34. Zhang T, Tang Y, Cui H, Lu X, Xu L, Liu X, et al. Theory of mind impairments in youth at clinical high risk of psychosis. Psychiatry. (2016) 79:4055. doi: 10.1080/00332747.2015.1123592

35. Dodell-Feder D, DeLisi LE, Hooker CI. Neural disruption to theory of mind predicts daily social functioning in individuals at familial high-risk for schizophrenia. Soc Cogn Affect Neurosci. (2014) 9:19141925. doi: 10.1093/scan/nst186

36. Glenthøj LB, Fagerlund B, Hjorthøj C, Jepsen JRM, Bak N, Kristensen TD, et al. Social cognition in patients at ultra-high risk for psychosis: what is the relation to social skills and functioning? Schizophr Res Cogn. (2016) 5:2127. doi: 10.1016/j.scog.2016.06.004

37. Müller VI, Cieslik EC, Laird AR, Fox PT, Radua J, Mataix-Cols D, et al. Ten simple rules for neuroimaging meta-analysis. Neurosci Biobehav Rev. (2018) 84:151-61. doi: 10.1016/j.neubiorev.2017.11.012

38. Fusar-Poli P. The Clinical High-Risk State for Psychosis (CHR-P), Version, I. I Schizophr Bull. (2017) 43:44-7. doi: 10.1093/schbul/sbw158

39. Fakra E, Jouve E, Guillaume F, Azorin JM, Blin O. Relation between facial affect recognition and configural face processing in antipsychoticfree schizophrenia. Neuropsychology. (2015) 29:197204. doi: 10.1037/neu00 00136

40. Li H, Chan RC, McAlonan GM, Gong QY. Facial emotion processing in schizophrenia: a meta-analysis of functional neuroimaging data. Schizophr Bull. (2009) 36:10291039. doi: 10.1093/schbul/sbn190

41. Taylor SF, Kang J, Brege IS, Tso IF, Hosanagar A, Johnson TD. Meta-analysis of functional neuroimaging studies of emotion perception and experience in schizophrenia. Biol Psychiatry. (2012) 71:136145. doi: 10.1016/j.biopsych.2011.09.007

42. van Veluw SJ, Chance SA. Differentiating between self and others: an ALE meta-analysis of fMRI studies of self-recognition and theory of mind. Brain Imaging Behav. (2014) 8:24-38. doi: 10.1007/s11682-013-9266-8

43. Eickhoff SB, Laird AR, Fox PM, Lancaster JL, Fox PT. Implementation errors in the GingerALE software: description and recommendations. Hum Brain Mapp. (2017) 38:711. doi: 10.1002/hbm.23342
44. Eickhoff SB, Laird AR, Grefkes C, Wang LE, Zilles K, Fox PT. Coordinatebased activation likelihood estimation meta-analysis of neuroimaging data: a random-effects approach based on empirical estimates of spatial uncertainty. Hum Brain Mapp. (2009) 30:29072926. doi: 10.1002/hbm. 20718

45. Eickhoff SB, Bzdok D, Laird AR, Kurth F, Fox PT. Activation likelihood estimation meta-analysis revisited. Neuroimage. (2012) 59:23492361. doi: 10.1016/j.neuroimage.2011.09.017

46. Turkeltaub PE, Eickhoff SB, Laird AR, Fox M, Wiener M, Fox P. Minimizing within-experiment and within-group effects in Activation Likelihood Estimation meta-analyses. Hum Brain Mapp. (2012) 33:113. doi: $10.1002 / \mathrm{hbm} .21186$

47. Marjoram D, Job DE, Whalley HC, Gountouna VE, McIntosh AM, Simonotto E, et al. A visual joke fMRI investigation into theory of mind and enhanced risk of schizophrenia. Neuroimage. (2006) 31:18501858. doi: 10.1016/j.neuroimage.2006.02.011

48. Fusar-Poli P, Borgwardt S, Bechdolf A, Addington J, RiecherRössler A, Schultze-Lutter F, et al. The psychosis high-risk state: a comprehensive state-of-the-art review. JAMA Psychiatry. (2013) 70:107-20. doi: 10.1001/jamapsychiatry.2013.269

49. Schurz M, Radua J, Aichhorn M, Richlan F, Perner J. Fractionating theory of mind: a meta-analysis of functional brain imaging studies. Neurosci Biobehav Rev. (2014) 42:934. doi: 10.1016/j.neubiorev.2014.01.009

50. Ethofer T, Anders S, Erb M, Droll C, Royen L, Saur R, et al. Impact of voice on emotional judgment of faces: an event-related fMRI study. Hum Brain Mapp. (2006) 27:707714. doi: 10.1002/hbm.20212

51. Hesling I, Dilharreguy B, Clément S, Bordessoules M, Allard M. Cerebral mechanisms of prosodic sensory integration using lowfrequency bands of connected speech. Hum Brain Mapp. (2005) 26:157169. doi: 10.1002/hbm.20147

52. Mirz F, Ovesen T, Ishizu K, Johannsen P, Madsen S, Gjedde A, et al. Stimulusdependent central processing of auditory stimuli: a PET study. Scand Audiol. (1999) 28:161169. doi: 10.1080/010503999424734

53. Bonelli SB, Thompson PJ, Yogarajah M, Powell RH, Samson RS, McEvoy $\mathrm{AW}$, et al. Memory reorganization following anterior temporal lobe resection: a longitudinal functional MRI study. Brain. (2013) 136:1889900. doi: 10.1093/brain/awt105

54. Brunet E, Sarfati Y, Hardy-Baylé MC, Decety J. Abnormalities of brain function during a nonverbal theory of mind task in schizophrenia. Neuropsychologia. (2003) 41:15741582. doi: 10.1016/S0028-3932(03)00 $119-2$

55. Krall SC, Volz LJ, Oberwelland E, Grefkes C, Fink GR, Konrad K. The right temporoparietal junction in attention and social interaction: a transcranial magnetic stimulation study. Hum Brain Mapp. (2016) 37:796807. doi: $10.1002 / \mathrm{hbm} .23068$

56. Lee SM, McCarthy G. Functional heterogeneity and convergence in the right temporoparietal junction. Cereb Cortex. (2016) 26:11081116. doi: 10.1093/cercor/bhu292

57. Mengotti P, Dombert PL, Fink GR, Vossel S. Disruption of the right temporoparietal junction impairs probabilistic belief updating. J Neurosci. (2017) 37:54195428. doi: 10.1523/JNEUROSCI.3683-16.2017

58. Cavanna AE, Trimble MR. The precuneus: a review of its functional anatomy and behavioural correlates. Brain. (2006) 129:564583. doi: 10.1093/brain/awl004

59. Singer T, Seymour B, O’Doherty J, Kaube H, Dolan RJ, Frith CD. Empathy for pain involves the affective but not sensory components of pain. Science. (2004) 303:11571162. doi: 10.1126/science.1093535

60. Cunningham SI, Tomasi D, Volkow ND. Structural and functional connectivity of the precuneus and thalamus to the default mode network. Hum Brain Mapp. (2017) 38:938956. doi: 10.1002/hbm.23429

61. Fusar-Poli P, Howes OD, Allen P, Broome M, Valli I, Asselin MC, et al. Abnormal prefrontal activation directly related to pre-synaptic striatal dopamine dysfunction in people at clinical high risk for psychosis. Mol Psychiatry. (2011) 16:67-75. doi: 10.1038/mp.2009.108

62. Lee KH, Brown WH, Egleston PN, Green RD, Farrow TF, Hunter MD, et al. A functional magnetic resonance imaging study of social cognition in schizophrenia during an acute episode and after recovery. Am J Psychiatry. (2006) 163:19261933. doi: 10.1176/ajp.2006.163.11.1926 
63. Haijma SV, Van Haren N, Cahn W, Koolschijn PC, Hulshoff Pol HE, Kahn RS. Brain volumes in schizophrenia: a meta-analysis in over 18 000 subjects. Schizophr Bull. (2013) 39:11291138. doi: 10.1093/schbul/ sbs 118

64. Herold R, Feldmann A, Simon M, Tényi T, Kövér F, Nagy F, et al. Regional gray matter reduction and theory of mind deficit in the early phase of schizophrenia: a voxel-based morphometric study. Acta Psychiatr Scand. (2009) 119:199-208. doi: 10.1111/j.1600-0447.2008. 01297.x

65. Hirao K, Miyata J, Fujiwara H, Yamada M, Namiki C, Shimizu $\mathrm{M}$, et al. Theory of mind and frontal lobe pathology in schizophrenia: a voxel-based morphometry study. Schizophr Res. (2008) 105:165174. doi: 10.1016/j.schres.2008.07.021

66. Hooker CI, Bruce L, Lincoln SH, Fisher M, Vinogradov S. Theory of mind skills are related to gray matter volume in the ventromedial prefrontal cortex in schizophrenia. Biol Psychiatry. (2011) 70:11691178. doi: 10.1016/j.biopsych.2011.07.027

67. Koelkebeck K, Hirao K, Miyata J, Kawada R, Saze T, Dannlowski $\mathrm{U}$, et al. Impact of gray matter reductions on theory of mind abilities in patients with schizophrenia. Soc Neurosci. (2013) 8:631639. doi: 10.1080/17470919.2013.837094

68. Yamada M, Hirao K, Namiki C, Hanakawa T, Fukuyama H, Hayashi T, et al. Social cognition and frontal lobe pathology in schizophrenia: a voxel-based morphometric study. Neuroimage. (2007) 35:292298. doi: 10.1016/j.neuroimage.2006.10.046

69. Das P, Calhoun V, Malhi GS. Mentalizing in male schizophrenia patients is compromised by virtue of dysfunctional connectivity between task-positive and task-negative networks. Schizophr Res. (2012) 140:5158. doi: 10.1016/j.schres.2012.06.023

70. Forbes CE, Grafman J. The role of the human prefrontal cortex in social cognition and moral judgment. Ann Rev Neurosci. (2010) 33:299324. doi: 10.1146/annurev-neuro-060909-153230

71. Uddin LQ, Iacoboni M, Lange C, Keenan JP. The self and social cognition: the role of cortical midline structures and mirror neurons. Trends Cogn Sci. (2007) 11:153157. doi: 10.1016/j.tics.2007.01.001

72. Van Overwalle F. Social cognition and the brain: a meta-analysis. Hum Brain Mapp. (2009) 30:829858. doi: 10.1002/hbm.20547

73. Brunet-Gouet E, Decety J. Social brain dysfunctions in schizophrenia: a review of neuroimaging studies. Psychiatry Res. (2006) 148:7592. doi: 10.1016/j.pscychresns.2006.05.001

74. Walter H, Ciaramidaro A, Adenzato M, Vasic N, Ardito RB, Erk S, et al. Dysfunction of the social brain in schizophrenia is modulated by intention type: an fMRI study. Soc Cogn Affect Neurosci. (2009) 4:166176. doi: $10.1093 /$ scan/nsn047
75. Barbey AK, Krueger F, Grafman J. An evolutionarily adaptive neural architecture for social reasoning. Trends Neurosci. (2009) 32:603610. doi: 10.1016/j.tins.2009.09.001

76. Jáni $M$, Kašpárek $T$. Emotion recognition and theory of mind in schizophrenia: a meta-analysis of neuroimaging studies. World J Biol Psychiatry. (2018) 19(sup3):S86-96. doi: 10.1080/15622975.2017.1324176

77. Kronbichler L, Tschernegg M, Martin AI, Schurz M, Kronbichler M. Abnormal brain activation during theory of mind tasks in schizophrenia: a meta-analysis. Schizophr Bull. (2017) 43:12401250. doi: 10.1093/schbul/sbx073

78. Vucurovic K, Caillies S, Kaladjian A. Neural correlates of theory of mind and empathy in schizophrenia: an activation likelihood estimation meta-analysis. J Psychiatr Res. (2020) 120:163-74. doi: 10.1016/j.jpsychires.2019.10.018

79. Bitsch F, Berger P, Nagels A, Falkenberg I, Straube B. Impaired right temporoparietal junction-hippocampus connectivity in schizophrenia and its relevance for generating representations of other minds. Schizophr Bull. (2018) 45:934-45. doi: 10.1093/schbul/sby132

80. Pauly KD, Kircher TT, Schneider F, Habel U. Me, myself and I: temporal dysfunctions during self-evaluation in patients with schizophrenia. Soc Cogn Affect Neurosci. (2014) 9:17791788. doi: 10.1093/scan/nst174

81. Abu-Akel A, Bailey AL. The possibility of different forms of theory of mind impairment in psychiatric and developmental disorders. Psychol Med. (2000) 30:735738. doi: 10.1017/S0033291799002123

82. Chambon V, Pacherie E, Barbalat G, Jacquet P, Franck N, Farrer C. Mentalizing under influence: abnormal dependence on prior expectations in patients with schizophrenia. Brain. (2011) 13:37283741. doi: 10.1093/brain/awr306

83. Gradin VB, Kumar P, Waiter G, Ahearn T, Stickle C, Milders M, et al. Expected value and prediction error abnormalities in depression and schizophrenia. Brain. (2011) 134(Pt 6):1751-64. doi: 10.1093/brain/awr059

84. Jardri R, Pouchet A, Pins D, Thomas P. Cortical activations during auditory verbal hallucinations in schizophrenia: a coordinate-based meta-analysis. Am J Psychiatry. (2011) 168:7381. doi: 10.1176/appi.ajp.2010.09101522

Conflict of Interest: The authors declare that the research was conducted in the absence of any commercial or financial relationships that could be construed as a potential conflict of interest.

Copyright (c) 2021 Vucurovic, Caillies and Kaladjian. This is an open-access article distributed under the terms of the Creative Commons Attribution License (CC BY). The use, distribution or reproduction in other forums is permitted, provided the original author(s) and the copyright owner(s) are credited and that the original publication in this journal is cited, in accordance with accepted academic practice. No use, distribution or reproduction is permitted which does not comply with these terms. 